BMJ Open

Diabetes

Research

\& Care

\section{Lower extremity reamputation in people with diabetes: a systematic review and meta-analysis}

To cite: Liu R, Petersen BJ, Rothenberg GM, et al. Lower extremity reamputation in people with diabetes: a systematic review and meta-analysis. BMJ Open Diab Res Care 2021;9:e002325. doi:10.1136/ bmjdrc-2021-002325

- Supplemental material is published online only. To view, please visit the journal online (http://dx.doi.org/10.1136/ bmjdrc-2021-002325).

Received 11 April 2021 Accepted 9 May 2021
Check for updates

(C) Author(s) (or their employer(s)) 2021. Re-use permitted under CC BY-NC. No commercial re-use. See rights and permissions. Published by BMJ.

${ }^{1}$ Podimetrics Inc, Somerville, Massachusetts, USA

${ }^{2}$ Harvard University T H Chan School of Public Health, Boston, Massachusetts, USA ${ }^{3}$ Department of Internal Medicine, University of Michigan Medical School, Ann Arbor, Michigan, USA ${ }^{4}$ Department of Surgery, USC Keck School of Medicine, Los Angeles, California, USA

Correspondence to Brian J Petersen; authors@podiography.org

\section{ABSTRACT}

In this study, we determined the reamputation-free survival to both limbs and to the contralateral limb only following an index amputation of any-level and assessed whether reamputation rates have changed over time. We completed a systematic search using PubMed and screened a total of 205 articles for data on reamputation rates. We reported qualitative characteristics of 56 studies that included data on reamputation rates and completed a meta-analysis on 22 of the studies which enrolled exclusively participants with diabetes. The randomeffects meta-analysis fit a parametric survival distribution to the data for reamputations to both limbs and to the contralateral limb only. We assessed whether there was a temporal trend in the reamputation rate using the MannKendall test. Incidence rates were high for reamputation to both limbs and to the contralateral limb only. At 1 year, the reamputation rate for all contralateral and ipsilateral reamputations was found to be $19 \%(\mathrm{IQR}=5.1 \%-31.6 \%)$, and at 5 years, it was found to be $37.1 \%$ (IQR $=27.0 \%$ $47.2 \%)$. The contralateral reamputation rate at 5 years was found to be $20.5 \%$ (IQR=13.3\%-27.2\%). We found no evidence of a trend in the reamputation rates over more than two decades of literature analyzed. The incidence of lower extremity reamputation is high among patients with diabetes who have undergone initial amputations secondary to diabetes, and rates of reamputation have not changed over at least two decades.

\section{INTRODUCTION}

Every year, more than one million people undergo a lower extremity amputation (LEA) secondary to diabetes, resulting in a limb loss every 20 s worldwide. ${ }^{1}$ LEAs are life-altering events that are associated with substantial morbidity and mortality, ${ }^{2}$ poor quality-of-life, ${ }^{3}$ prolonged inpatient stays, ${ }^{4}$ and high readmission rates. ${ }^{5}$ After a period of prolonged steady decline of LEA rates, over the past decade rates of LEA have rebounded by $50 \%{ }^{6}$

Despite these well-known negative consequences of amputations and known increasing incidence, risk for subsequent amputation following an initial amputation has been reported to be high. A large-scale study in 71300 Medicare beneficiaries undergoing dysvascular amputation found that $26 \%$ of patients with diabetes required subsequent reamputation within 12 months. ${ }^{2}$ Similarly, Borkosky et $a l^{7}$ estimated that one in every five patients who had undergone initial ray amputation required reamputation. Considering all-level index LEAs among patients with diabetes, Kanade $e t a l^{8}$ found that within 2 years, as many as $45.9 \%$ with a prior LEA required reamputation, with $22 \%$ incidence of contralateral LEA.

Synthesizing these data and data from other trials examining reamputation, two recent meta-analyses of postamputation outcomes among patients with diabetes estimated a 1-year reamputation rate of $19.8 \%$ after partial ray amputation ${ }^{7}$ and $28.4 \%$ after transmetatarsal amputations (TMAs). ${ }^{9}$ However, these studies only reported data on certain distal index amputations. They were also limited in reporting only at specific durations after an index amputation instead of reporting a reamputation-free survival distribution over time. Additionally, neither study considered whether the subsequent amputation occurred to the same or contralateral limb. Finally, neither study considered how reamputation rates are evolving over time.

Thus, closer scrutiny and analysis of all available evidence is needed to understand the progression of limb loss for patients with diabetes after any level of index amputation. The purpose of this study is to synthesize available data on reamputation rates and estimate the reamputation-free survival following index amputations of all levels for those with diabetes and to determine whether reamputation rates have improved over time.

\section{METHODS}

\section{Nomenclature}

For the purpose of this review, we adopted definitions from the International Standards Organization. ${ }^{10}$ 'Amputation' was defined as surgical removal of the whole or part of a limb. 'Index amputation' is a first or primary 
amputation. 'Reamputation' was defined as a subsequent amputation. Any soft tissue surgeries such as reoperation, debridement, revascularization surgeries, or secondary wound closure are not considered an amputation or reamputation. 'Revision' was defined as a surgical procedure on a previously amputated limb without changing the level of amputation, and was also excluded from the definition of reamputation. 'Contralateral amputation' was defined as an amputation to the contralateral limb after an index amputation. Contralateral amputations were considered reamputations for the purpose of this review.

\section{Search strategy}

Our systematic review relied a study protocol preregistered with Preferred Reporting Items for Systematic Reviews and Meta-Analyses (PRISMA) protocol (PROSPERO 2020 CRD42020206148). On June 10, 2020, under a preregistered protocol, a systematic search was conducted using PubMed with the following search query: (reamputat* OR re-amputat* OR "secondary amputation" OR "repeat amputation" OR "subsequent amputation") AND ("diabetes" OR "neuropathy" OR "Diabetic Foot"[Mesh]). No date restrictions were placed on the searches. To augment the PubMed search, we screened and reviewed citations from included studies for eligibility.

\section{Inclusion criteria}

To be eligible for inclusion in the systematic review, studies must have been written in English and published in a journal indexed by PubMed. Only original research articles were included, including cohort studies, case-control studies, prospective clinical trials, and retrospective chart reviews. Case reports, review articles, and meta-analyses were excluded. Studies that only investigated amputation or that did not have specific data regarding reamputations were excluded. Studies must have reported on the time point at which reamputation was performed relative to the timing of the index amputation.

We included in the meta-analysis only those studies included in the systematic review that exclusively enrolled participants with diabetes mellitus.

\section{Data compilation}

Data were extracted by a primary reviewer and independently assessed by a secondary reviewer for accuracy. A third author adjudicated any disagreements between the primary and secondary reviewers. We completed fulltext reviews for those studies which the primary reviewer believed could plausibly meet the inclusion criteria based on the title and abstract.

Articles selected for full-text review were summarized and data were extracted including country, year, number of participants, age, percentage of participants with diabetes, numbers and levels of index amputations, numbers and levels of reamputation, mortality, and mean follow-up duration in months. For studies including a reamputation-free survival curve, these data were digitized at an interval of 1 year.

\section{Risk of bias assessment}

We did not complete a risk of bias assessment for this systematic review and meta-analysis because we are not synthesizing the results of an intervention but instead are reporting on and synthesizing epidemiological data and thus for our purposes publication bias is unlikely.

\section{Statistical analysis}

Given the broad inclusion criteria of the studies included, we used a random-effects model because we anticipated heterogeneity in the reamputation incidence data reported resulting from differences in the studies' year undertaken, care environment, nature of the index amputation, and inclusion criteria of the studies comprising our analysis.

Because reamputation incidence data at multiple durations from the index amputation were available, we did not conduct a conventional random-effects metaanalysis at isolated time points, which may have resulted in inconsistent non-monotonic estimates of the reamputation rates. For example, using such a modeling approach, depending on the data and studies reporting data at the time points considered, the random effects point-estimate of the year 3 reamputation rate could have been found to be lower than the year 5 reamputation rate.

Instead, to address this potential issue and satisfy the random-effects assumption, we fit a parametric survival distribution to the data in a multilevel model with hyperparameters over the inputs to the survival distribution. We used a log-logistic parametric survival distribution. The distribution was formulated with a shape parameter and a median parameter as input. We assumed beta distributions over the shape and median parameters of the log-logistic distribution and solved for the four unknown inputs to the two beta distributions by maximizing the log-likelihood over the reported reamputation rates from the included studies. We then sampled the posterior distribution using a Markov chain Monte Carlo Ensemble sampler to estimate the uncertainty in the survival distribution estimate.

We completed this aforementioned analysis for studies with $100 \%$ of participants with diabetes mellitus that reported on contralateral or all reamputation rates. We included forest plots for all reamputations as well as the maximum-likelihood parametric survival distributions and IQRs for each category of reamputation.

To determine whether reamputation rates are improving over time, we extracted the residual between the maximum likelihood estimator from the parametric survival model analysis and the point estimates from the individual studies. We tested for a trend using the nonparametric Mann-Kendall test at a significance level of $\alpha=0.05$. 


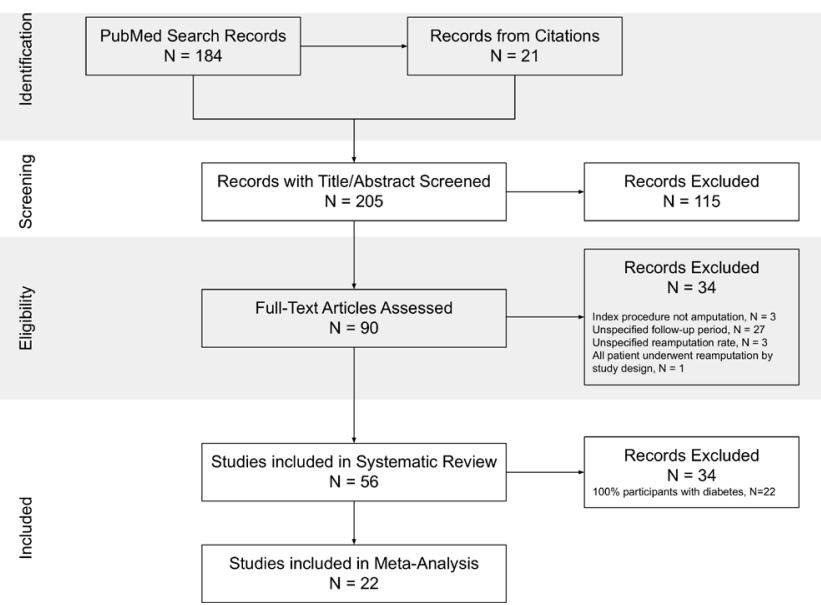

Figure 1 Preferred Reporting Items for Systematic Reviews and Meta-Analyses flowchart.

\section{RESULTS}

\section{Included studies}

Figure 1 shows the PRISMA flowchart for those studies included in the systematic review and meta-analysis. The keyword search yielded 184 unique citations screened for eligibility, and the citations for these studies were screened to obtain 21 further articles of relevance. Overall, 205 articles were identified and screened. Screening by title and abstract excluded 115 articles for relevance, leaving 90 for full-text review. Another 34 articles were excluded because they did not meet inclusion criteria or lacked sufficient reporting to inform our outcomes of interest. The final quantitative synthesis included 56 studies, and after screening on those with enrollment consisting of $100 \%$ patients with diabetes, the meta-analysis included 22 studies.

\section{Systematic review study characteristics}

Online supplemental table 1 summarizes the salient characteristics of the 56 studies included in the systematic review. $^{25} 811-63$ The publication year ranged from 1967 to 2020 . Forty-two $(75 \%)$ were retrospective and 14 (25\%) were prospective studies. The majority of included studies $(26,46 \%)$ reported outcomes for populations in the USA, and a handful of studies $(15,27 \%)$ reported data in European countries. Only four studies reported outcomes outside of the USA or Europe. ${ }^{12174759}$

The combined studies included in the systematic review summarize the risk of reamputation in 58272 participants with 58684 index amputations. Study cohorts ranged from 11 to 17786 participants with average ages ranging from 46 to 77 years. Most studies reported a majority of participants with diabetes (range: 23\%-100\%). Indications for index amputation were clarified in 30 studies, with the most commonly reported reasons including gangrene, infection, ischemia, diabetes related, and osteomyelitis. Weighted values were calculated to account for variations in sample size. The initial amputation levels included both distal (partial foot, TMA, and amputation at the ankle) and proximal LEAs (above the ankle).
Methods and follow-up durations varied across studies, but follow-up at 30 days (perioperative), 1, 3, and 5 years were most common. In total, 22 studies reported follow-up at 1 year (12 months), 7 studies at 3 years (36 months), and 12 studies at 5 years (60 months). There were isolated data for other time points such as 3, 6, and 48 months after index amputation. Four articles that followed patients up to 5 years also reported outcomes at 1 year, 3 years, or both.

\section{Meta-analysis}

Of the 56 studies included in the systematic review, 22 included participants with diabetes mellitus exclusively and were thus included in the metaanalysis. ${ }^{11} 1416-1922283738424750515355$ 57-59 6162 There are 31 discrete incidence values from 22 studies reporting either ipsilateral or contralateral reamputations, and 8 incidence values from 5 studies ${ }^{11} 19223842$ reporting on contralateral reamputations. A total of 21145 primary amputation cases were followed for the all reamputation meta-analysis, and 1129 primary amputation cases were followed for contralateral reamputation meta-analysis.

Figure 2 shows the reamputation-free survival curves for contralateral and all reamputations through 6 years, and figure 3 shows a forest plot for the reamputation rates at three distinct time points from the index amputation for all reamputations. At 1 year, the reamputation rate for all contralateral and ipsilateral reamputations was found to be $19 \%(95 \% \mathrm{CI}=0.4 \%$ to $45.2 \%$; IQR=5.1\%-31.6\%), and at 5 years, it was found to be $37.1 \%(95 \% \mathrm{CI}=9.4 \%$ to $58.9 \%$; IQR $=27.0 \%-47.2 \%$ ). The contralateral reamputation rate at 5 years was found to be $20.5 \%(95 \% \mathrm{CI}=6.2 \%$ to $36.1 \%$; IQR $=13.3 \%-27.2 \%$ ).

We observed no trend in the reamputation rate as a function of study year at a significance level of $\alpha=0.05$ $(\mathrm{p}=0.4 ;$ Kendall $\tau=-0.11)$.

\section{DISCUSSION}

This study was designed to determine the survival distribution of all-level reamputations to both the ipsilateral and contralateral limbs and to assess whether reamputation rates are improving over time. We found high incidence rates for both categories of reamputation. At 1 year, the reamputation rate for all contralateral and ipsilateral reamputations was found to be $19 \%(\mathrm{IQR}=5.1 \%-31.6 \%)$, and at 5 years, it was found to be $37.1 \%$ (IQR $=27.0 \%-$ $47.2 \%)$. The contralateral reamputation rate at 5 years was found to be $20.5 \%(\mathrm{IQR}=13.3 \%-27.2 \%)$. There was no evidence of a trend in the reamputation rates over the period spanned by the studies in the meta-analysis ( $p=0.4$; Kendall $\tau=-0.11)$.

Our results reflect the high recidivism rates following index amputations documented throughout the literature: for many patients with diabetes after an initial partial-foot amputation, a subsequent proximal amputation is required, sometimes at the transfemoral level. $^{1653}$ Murdoch et at ${ }^{42}$ reported that 1 year after index 

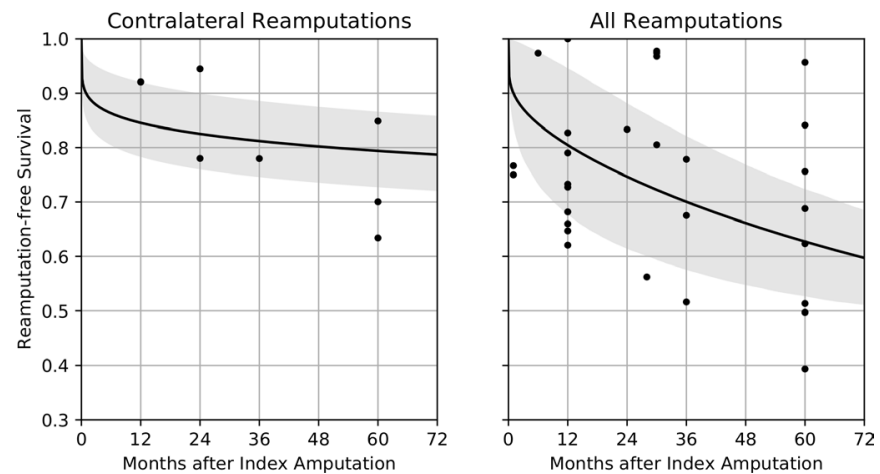

Figure 2 Reamputation-free survival curves for contralateral reamputations (left) and all reamputations (right) among patients with diabetes. The solid line is the maximumlikelihood estimate of the log-logistic survival model. The shaded area represents the IQR.

amputation, $60 \%$ of all patients had a second amputation, $21 \%$ had a third amputation, and $7 \%$ had a fourth amputation. Similarly, Kono and Muder ${ }^{34}$ reported that approximately $50 \%$ of patients required ipsilateral reamputation by 3 years after the index amputation. In addition to the reamputation rates, the reoperation rate has also remained high. A chart review of 52 patients found a total of 85 additional operations required, with some patients undergoing as high as four additional operations, ${ }^{64}$ although some patients included in this study had prior amputation history, so the subsequent amputations could be confounded by the progression of other underlying health conditions and thereby contribute to an overestimation of the reamputation rate. Nonetheless, evidence has suggested that patients with diabetes are at high risk of perioperative death, ${ }^{13} 1421$ and therefore, any additional operations would presumably impose additional risk of mortality.

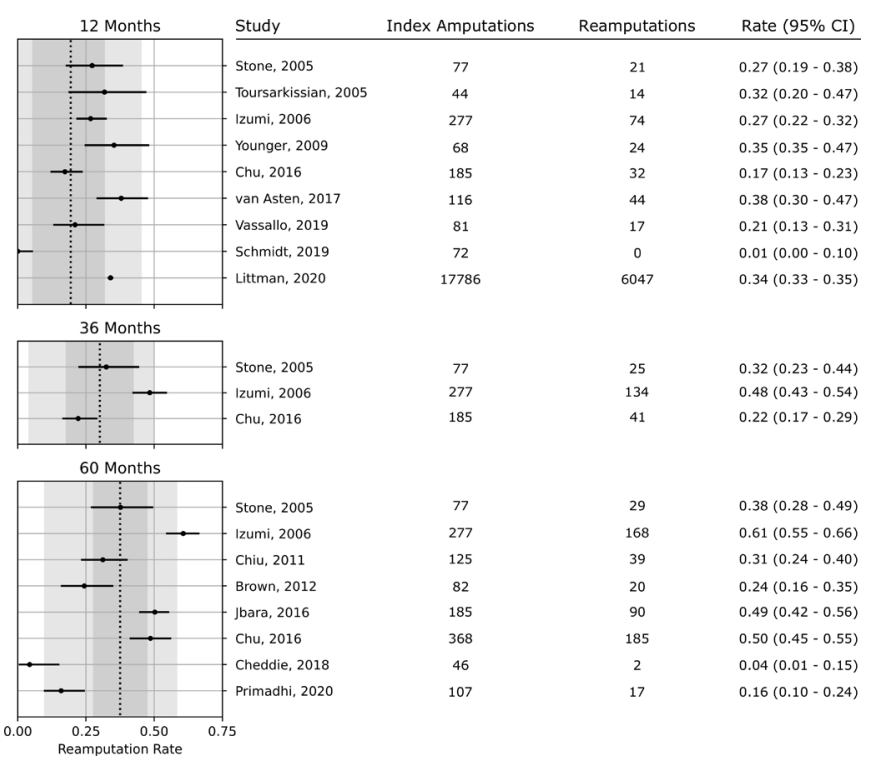

Figure 3 Estimates of all reamputation rates among patients with diabetes. The lighter shading represents the $95 \% \mathrm{Cl}$, and the darker shading represents the IQR.
Our results suggest there has been no major change in the reamputation rate over a prolonged period. Follow-up work should investigate whether the incidence of reamputation is changing relative to the incidence of index amputation, but this more sophisticated analysis was outside the scope of the present investigation. Improvements in reamputation rate may be impeded by challenges of selecting the optimal level of index amputation, poor surgical wound healing and rehabilitation following amputation, and likelihood of recurrence of diabetic foot wounds particularly with the introduction of further foot deformity and gait deviation post amputation. Routinely, the most distal location is chosen for wounds in order to preserve the integrity of the remaining foot, resulting in an amputation of the digits. However, some studies have demonstrated that a lower level of index amputation is associated with higher risks of re-ulceration and a lower rate of healing. ${ }^{65}$ In addition, persons with diabetes can also experience a significant progression of the underlying disease process. ${ }^{21}$ This in turn leads to a higher risk of more proximal ipsilateral reamputation or amputation of the contralateral limbs.

Our review identified inconsistent anatomic definitions used among the studies, making comparisons across studies challenging. For example, a contralateral amputation was defined as amputation at or proximal to the transmetatarsal level on the opposite lower limb, ${ }^{30}$ any amputation of the contralateral foot or leg, ${ }^{842}$ or a new amputation at a lower level than the index amputation. ${ }^{56}$ Other studies either did not provide a precise definition $^{21}$ or further divided subsequent amputations on the contralateral side by anatomical levels. ${ }^{19} 38$ Standardized definitions are needed for future research to mitigate the methodological discrepancies and allow for a more accurate comparison of published results regarding index and reamputation status.

We executed a comprehensive search strategy without any date restrictions and extracted articles that were cited by each of the identified studies. This allowed us to retrieve a high volume of articles and facilitated our examination of changes in the reamputation rate over time. The main strength of this study is that by reviewing and synthesizing the extant literature, we were able to provide an estimate of survival from reamputation for both limbs and for the contralateral limb. In addition, our review primarily focused on patients with diabetes, and therefore the results are relevant to clinical decision making and selection of the appropriate measures used to prevent reamputation in people with diabetes at high risk of future foot complications. This work contributes to existing knowledge of the high re-ulceration rate of the ipsilateral and contralateral limb. It has been estimated that after ulcer healing, $40 \%$ of patients have a recurrence within 1 year, and as high as $65 \%$ within 5 years. Taken together, the current evidence suggests the tremendous financial as well as the medical burden of foot complications on the diabetic population and highlights the importance of diabetic ulcer prevention. 
This study had several limitations. First, like most meta-analyses, ours was limited by publication bias of the studies underlying our analysis. We believe that this limitation is somewhat mitigated in our case by the fact that we are not analyzing the results from the intervention groups of randomized studies but instead relying on data observational studies. Second, many studies identified were retrospective studies and thereby lacked granularity on the progression of reamputation status per year, which limited the amount of data available for our metaanalysis. This limited literature evidence revealed a need for more prospective research with extended follow-up periods, in order to synthesize long-term results and investigate the key determinants of the performance of different diabetic care systems. Finally, we did not perform a formal assessment of risks of bias because all papers included in this review were observational in nature and have a low risk of bias for our purposes.

The incidence of lower extremity reamputation is high among patients with diabetes who have undergone initial amputations secondary to diabetes. Longterm reamputation-free survival decreased with longer follow-up, and patients with diabetes are at a distinctly higher risk of reamputation at any follow-up lengths. For all-level or contralateral reamputation rates, the lack of significant downward trends over the past 50 years calls for improved prevention efforts. This systematic review and meta-analysis revealed high heterogeneity in study design and confirmed the need to standardize outcome reporting methods in future studies. Additional focus on prevention for those with recent amputations is necessary to reduce overall incidence of LEA.

Contributors RL and BJP: study concept and design, acquisition of data, analysis of data, interpretation of results, and preparation of the manuscript. GMR: study concept and design, and preparation of the manuscript. DGA: preparation of the manuscript.

Funding The authors have not declared a specific grant for this research from any funding agency in the public, commercial or not-for-profit sectors.

Competing interests RL is an employee of Podimetrics Inc. BJP is an employee and shareholder of Podimetrics Inc. GMR is a consulting medical director for Podimetrics Inc. DGA is on the scientific advisory board of Podimetrics Inc.

Patient consent for publication Not required.

Provenance and peer review Not commissioned; externally peer reviewed.

Data availability statement Data are available upon reasonable request to the corresponding author.

Supplemental material This content has been supplied by the author(s). It has not been vetted by BMJ Publishing Group Limited (BMJ) and may not have been peer-reviewed. Any opinions or recommendations discussed are solely those of the author(s) and are not endorsed by BMJ. BMJ disclaims all liability and responsibility arising from any reliance placed on the content. Where the content includes any translated material, BMJ does not warrant the accuracy and reliability of the translations (including but not limited to local regulations, clinical guidelines, terminology, drug names and drug dosages), and is not responsible for any error and/or omissions arising from translation and adaptation or otherwise.

Open access This is an open access article distributed in accordance with the Creative Commons Attribution Non Commercial (CC BY-NC 4.0) license, which permits others to distribute, remix, adapt, build upon this work non-commercially, and license their derivative works on different terms, provided the original work is properly cited, appropriate credit is given, any changes made indicated, and the use is non-commercial. See: http://creativecommons.org/licenses/by-nc/4.0/.
ORCID ID

Brian J Petersen http://orcid.org/0000-0002-9552-5859

\section{REFERENCES}

1 Lancet T. Putting feet first in diabetes. The Lancet 2005;366:1674.

2 Dillingham TR, Pezzin LE, Shore AD. Reamputation, mortality, and health care costs among persons with dysvascular lower-limb amputations. Arch Phys Med Rehabil 2005;86:480-6.

3 Pedras S, Carvalho R, Pereira MG. Quality of life in Portuguese patients with diabetic foot ulcer before and after an amputation surgery. Int J Behav Med 2016;23:714-21.

4 Schofield CJ, Libby G, Brennan GM, et al. Mortality and hospitalization in patients after amputation: a comparison between patients with and without diabetes. Diabetes Care 2006;29:2252-6.

5 Beaulieu RJ, Grimm JC, Lyu H, et al. Rates and predictors of readmission after minor lower extremity amputations. J Vasc Surg 2015;62:101-5.

6 Creager MA, Matsushita K, Arya S, et al. Reducing Nontraumatic Lower-Extremity Amputations by $20 \%$ by 2030 : Time to Get to Our Feet: A Policy Statement From the American Heart Association. Circulation 2021;143.

7 Borkosky SL, Roukis TS, Thomas S. Incidence of re-amputation following partial first ray amputation associated with diabetes mellitus and peripheral sensory neuropathy: a systematic review. Diabet Foot Ankle 2012;3:12169.

8 Kanade R, van Deursen R, Burton J, et al. Re-amputation occurrence in the diabetic population in South Wales, UK. Int Wound $J$ 2007:4:344-52.

9 Thorud JC, Jupiter DC, Lorenzana J, et al. Reoperation and Reamputation After Transmetatarsal Amputation: A Systematic Review and Meta-Analysis. J Foot Ankle Surg 2016;55:1007-12.

10 ISO 8549-4:2014, Prosthetics and orthotics - Vocabulary. Part 4: Terms relating to limb amputation. Available: https://www.iso.org/ obp/ui/\#iso:std:iso:8549:-4:ed-1:v1:en [Accessed 25 Oct 2020].

11 Izumi Y, Satterfield K, Lee S, et al. Risk of Reamputation in diabetic patients stratified by limb and level of amputation: a 10-year observation. Diabetes Care 2006;29:566-70.

12 Aftabuddin M, Islam N, Jafar MAHM, et al. The status of lowerlimb amputation in Bangladesh: a 6-year review. Surg Today 1997;27:130-4.

13 Ahn J, Raspovic KM, Liu GT, et al. Renal function as a predicto of early transmetatarsal amputation failure. Foot Ankle Spec 2019;12:439-51.

14 Baykal YB, Yaman E, Burc H, et al. Is scintigraphy a guideline method in determining amputation levels in diabetic foot? $J \mathrm{Am}$ Podiatr Med Assoc 2014;104:227-32.

15 Blume P, Salonga C, Garbalosa J, et al. Predictors for the healing of transmetatarsal amputations: retrospective study of 91 amputations. Vascular 2007:15:126-33.

16 Brown ML, Tang W, Patel A, et al. Partial foot amputation in patients with diabetic foot ulcers. Foot Ankle Int 2012;33:707-16.

17 Cheddie S, Manneh CG, Pillay B. Spectrum of disease and outcome of primary amputation for diabetic foot sepsis in rural KwaZuluNatal. S Afr J Surg 2018:56:16-19.

18 Chiu C-C, Huang C-L, Weng S-F, et al. A multidisciplinary diabetic foot ulcer treatment programme significantly improved the outcome in patients with infected diabetic foot ulcers. J Plast Reconstr Aesthet Surg 2011;64:867-72.

19 Chu Y-J, Li X-W, Wang P-H, et al. Clinical outcomes of toe amputation in patients with type 2 diabetes in Tianjin, China. Int Wound J 2016;13:175-81.

20 Czerniecki JM, Thompson ML, Littman AJ, et al. Predicting reamputation risk in patients undergoing lower extremity amputation due to the complications of peripheral artery disease and/or diabetes. Br J Surg 2019;106:1026-34.

21 Ebskov B, Josephsen P. Incidence of reamputation and death after gangrene of the lower extremity. Prosthet Orthot Int 1980;4:77-80.

22 Elsharawy MA. Outcome of Midfoot amputations in diabetic gangrene. Ann Vasc Surg 2011;25:778-82.

23 Eneroth M, Persson BM. Amputation for occlusive arterial disease. A prospective multicentre study of 177 amputees. Int Orthop 1992;16:383-7.

24 Fard B, Dijkstra PU, Voesten HGJM, et al. Mortality, Reamputation, and preoperative comorbidities in patients undergoing Dysvascular lower limb amputation. Ann Vasc Surg 2020;64:228-38.

25 Font-Jiménez I, Llaurado-Serra M, Roig-Garcia M, et al Retrospective study of the evolution of the incidence of nontraumatic lower-extremity amputations (2007-2013) and risk factors of reamputation. Prim Care Diabetes 2016;10:434-41. 
26 Glaser JD, Bensley RP, Hurks R, et al. Fate of the contralateral limb after lower extremity amputation. J Vasc Surg 2013;58:1571-7.

27 Häller TV, Kaiser P, Kaiser D, et al. Outcome of ray resection as definitive treatment in forefoot infection or ischemia: a cohort study. J Foot Ankle Surg 2020;59:27-30.

28 Jbara M, Gokli A, Beshai S, et al. Does obtaining an initial magnetic resonance imaging decrease the reamputation rates in the diabetic foot? Diabet Foot Ankle 2016;7:31240.

29 Jindeel A, Narahara KA. Nontraumatic amputation: incidence and cost analysis. Int J Low Extrem Wounds 2012;11:177-9.

30 Johannesson A, Larsson G-U, Ramstrand N, et al. Incidence of lower-limb amputation in the diabetic and nondiabetic general population: a 10-year population-based cohort study of initial unilateral and contralateral amputations and reamputations. Diabetes Care 2009;32:275-80.

31 Johannesson A, Larsson G-U, Ramstrand N, et al. Outcomes of a standardized surgical and rehabilitation program in transtibial amputation for peripheral vascular disease: a prospective cohort study. Am J Phys Med Rehabil 2010;89:293-303.

32 Jupiter DC, LaFontaine J, Barshes N, et al. Transmetatarsal and minor amputation versus major leg amputation: 30-day readmissions, Reamputations, and complications. J Foot Ankle Surg 2020;59:484-90.

33 Kacy SS, Wolma FJ, Flye MW. Factors affecting the results of below knee amputation in patients with and without diabetes. Surg Gynecol Obstet 1982;155:513-8.

34 Kono Y, Muder RR. Identifying the incidence of and risk factors for reamputation among patients who underwent foot amputation. Ann Vasc Surg 2012;26:1120-6.

35 Landry GJ. Predictors of healing and functional outcome following transmetatarsal amputations. Arch Surg 2011;146:1005.

36 Lin JH, Jeon SY, Romano PS, et al. Rates and timing of subsequent amputation after initial minor amputation. $J$ Vasc Surg 2020;72:268-75.

37 Littman AJ, Tseng C-L, Timmons A, et al. Risk of ipsilateral Reamputation following an incident toe amputation among U.S. military veterans with diabetes, 2005-2016. Diabetes Care 2020;43:1033-40.

38 Matsuzaki K, Miyamoto A, Hakamata N, et al. Diabetic foot wounds in haemodialysis patients: 2-year outcome after percutaneous transluminal angioplasty and minor amputation. Int Wound $J$ 2012;9:693-700.

39 Mazet R. The geriatric amputee. Artif Limbs 1967;11:33-41 https:// www.ncbi.nlm.nih.gov/pubmed/5622215

40 McCallum R, Tagoe M. Transmetatarsal amputation: a case series and review of the literature. J Aging Res 2012;2012:1-6.

41 Møller BN, Sølund K, Hansen SL. Wound infection after lower extremity amputation because of ischemia. Arch Orthop Trauma Surg 1985;104:262-4.

42 Murdoch DP, Armstrong DG, Dacus JB, et al. The natural history of great toe amputations. J Foot Ankle Surg 1997;36:204-8.

43 Nagashima $\mathrm{H}$, Inoue $\mathrm{H}$, Takechi $\mathrm{H}$. Incidence and prognosis of dysvascular amputations in Okayama Prefecture (Japan). Prosthet Orthot Int 1993;17:9-13.

44 Nayak RK, Kirketerp-Møller K. Preoperative blood glucose and prognosis in diabetic patients undergoing lower extremity amputation. Dan Med J 2016;63 https://www.ncbi.nlm.nih.gov/ pubmed/27034181

45 Netz P, Stark A, Ringertz H. Amputations for vascular insufficiency. Prosthet Orthot Int 1983;7:9-14.
46 Pollard J, Hamilton GA, Rush SM, et al. Mortality and morbidity after transmetatarsal amputation: retrospective review of 101 cases. $J$ Foot Ankle Surg 2006;45:91-7.

47 Primadhi RA. Susceptibility factors for early Reamputation in diabetic great toe gangrene. Curr Diabetes Rev 2021;17:55-62.

48 Rosen N, Gigi R, Haim A, et al. Mortality and reoperations following lower limb amputations. Isr Med Assoc J 2014;16:83-7.

49 Rucker-Whitaker C, Feinglass J, Pearce WH. Explaining racial variation in lower extremity amputation: a 5-year retrospective claims data and medical record review at an urban teaching hospital. Arch Surg 2003;138:1347-51.

50 Schmidt BM, McHugh JB, Patel RM, et al. Prospective analysis of surgical bone margins after partial foot amputation in diabetic patients admitted with moderate to severe foot infections. Foot Ankle Spec 2019;12:131-7.

51 Sizer JS, Wheelock FC. Digital amputations in diabetic patients. Surgery 1972;72:980-9.

52 Stirnemann P, Mlinaric Z, Oesch A, et al. Major lower extremity amputation in patients with peripheral arterial insufficiency with special reference to the transgenicular amputation. J Cardiovasc Surg 1987;28:152-8.

53 Stone PA, Back MR, Armstrong PA, et al. Midfoot amputations expand limb salvage rates for diabetic foot infections. Ann Vasc Surg 2005;19:805-11.

54 Thomas SR, Perkins JM, Magee TR, et al. Transmetatarsal amputation: an 8-year experience. Ann $R$ Coll Surg Engl 2001;83:164-6.

55 Toursarkissian B, Hagino RT, Khan K, et al. Healing of transmetatarsal amputation in the diabetic patient: is angiography predictive? Ann Vasc Surg 2005;19:769-73.

56 Vaccaro O, Lodato S, Mariniello P, et al. Diabetes-Related lower extremity amputations in the community: a study based on hospita discharge diagnoses. Nutr Metab Cardiovasc Dis 2002;12:331-6.

57 Van Asten SAV, Nichols A, La Fontaine J, et al. The value of inflammatory markers to diagnose and monitor diabetic foot osteomyelitis. Int Wound J 2017;14:40-5.

58 Vassallo IM, Gatt A, Cassar K, et al. Healing and mortality rates following toe amputation in type 2 diabetes mellitus. Exp Clin Endocrinol Diabetes 2019. doi:10.1055/a-0942-1789. [Epub ahead of print: 17 Jun 2019].

59 Viswanathan V, Wadud JR, Madhavan S, et al. Comparison of post amputation outcome in patients with type 2 diabetes from specialized foot care centres in three developing countries. Diabetes Res Clin Pract 2010;88:146-50.

60 Wied C, Tengberg PT, Holm G, et al. Tourniquets do not increase the total blood loss or re-amputation risk in transtibial amputations. World J Orthop 2017;8:62-7.

61 Wong KL, Nather A, Liang S, et al. Clinical outcomes of below knee amputations in diabetic foot patients. Ann Acad Med Singapore 2013;42:388-94 https://www.ncbi.nlm.nih.gov/pubmed/24045374

62 Younger ASE, Awwad MA, Kalla TP, et al. Risk factors for failure of transmetatarsal amputation in diabetic patients: a cohort study. Foot Ankle Int 2009;30:1177-82.

63 Choi MSS, Jeon SB, Lee JH. Predictive factors for successful limb salvage surgery in diabetic foot patients. BMC Surg 2014;14:113.

64 Anthony T, Roberts J, Modrall JG, et al. Transmetatarsal amputation: assessment of current selection criteria. Am J Surg 2006;192:e8-11.

65 Santi MD, Thoma BJ, Chambers RB. Survivorship of healed partial foot amputations in dysvascular patients. Clin Orthop Relat Res 1993;292:245-9. 